\title{
UMA PROPOSTA TEÓRICA PARA ANÁLISE DOS TEMPOS VERBAIS A PARTIR DOS MUNDOS DISCURSIVOS E DOS TIPOS DE DISCURSO
}

\section{A THEORETICAL PROPOSAL FOR ANALYSIS OF VERBAL TENSES FROM DISCURSIVE WORLDS AND TYPES OF DISCOURSE}

\author{
Thiago Gil Lessa Alves ${ }^{1}$
}

RESUMO

O presente artigo visa apresentar uma proposta teórica para a análise dos tempos verbais dentro da perspectiva dos mundos discursivos e dos tipos de discurso, como postulados por Bronckart (2003). O trabalho fundamenta-se na consideração de que os tempos verbais se estruturam nas línguas naturais, primeira e principalmente, como um dos mecanismos que atualizam e marcam os diferentes mundos discursivos a partir dos quais os participantes de uma interação verbal produzem seus textos, e não como um recurso prioritário de expressão do tempo cronológico, como geralmente são considerados. Metodologicamente, a proposta é construída a partir de uma discussão teórica da perspectiva de interpretação temporal das línguas naturais de Reichenbach (1947), que estabelece a existência de três pontos teóricos na linha do tempo; da simulação formal dos modos de expressão do tempo em português de Corôa (1985); e, também, dos parâmetros de referência dos mundos discursivos apresentados por Bronckart (2003). A conclusão a que se chega é a de que os tempos verbais podem ser analisados e definidos, dentro de cada mundo discursivo, com base em quatro parâmetros: a) processo; b) eixo de referência temporal global; c) fase atual do processo de textualização e d) eixo de referência temporal local.

Palavras-chave: Tempos verbais. Mundos discursivos. Tipos de discurso.

\section{ABSTRACT}

This article aims to present a theoretical proposal for the analysis of verbal tenses within the perspective of discursive worlds and of types of discourse, as they were postulated by Bronckart

\footnotetext{
${ }^{1}$ Professor Associado do Curso de Letras da Universidade Regional do Cariri - URCA. ORCID: https://orcid. org/0000-0003-1151-3525.
} 
(2003). It is based on the consideration that verbal tenses are structured in natural languages, first and foremost, as one of the mechanisms that express and mark the different discursive worlds from which the participants of a verbal interaction produce their texts, and not as a priority resource for the expression of chronological time, as they are generally considered. Methodologically, the proposal is built from a theoretical discussion of the Reichenbach's (1947) perspective of temporal interpretation of natural languages, which proposes the existence of three theoretical points in the timeline; of the Corôa's (1985) formal simulation of the modes of expression of time in Portuguese; and also of the reference parameters of the discursive worlds presented by Bronckart (2003). The conclusion reached is that the verb tenses can be analyzed and defined, within each discursive world, based on four parameters: a) process, b) global time reference axis, c) current phase of the textualization process and d) local time reference axis.

Keywords: Verbal tenses. Discursive worlds. Types of discourse.

\section{INTRODUÇÃO}

Os tempos verbais, desde os primórdios dos estudos da linguagem na antiguidade greco-romana, são tratados quase sempre em função de suas relações com o tempo cronológico. Tem sido assim mesmo depois do advento da Linguística em inícios do século XX.

Benveniste (1995[1966]) foi o primeiro que delineou uma abordagem diferente para essa categoria gramatical. Em um estudo sobre os tempos verbais do francês, percebeu que os tempos se organizam em dois grupos gerais relacionados a dois planos de enunciação diferentes: o da história, que é reservado à língua escrita e à terceira pessoa e que engloba a narrativa dos acontecimentos passados, sem qualquer participação do locutor; e o do discurso, que abarca as variedades dos discursos orais, em que o locutor sempre intervém com a intenção de influenciar o ouvinte, e dos discursos escritos que reproduzem os discursos orais ou que se baseiam em sua construção e fins.

Weinrich (1974) segue a ideia geral de Benveniste, mas critica o fato de ter limitado o plano enunciativo da história à língua escrita e à terceira pessoa, somente, segundo o autor, com o fim de justificar o passé simple como o tempo central desse plano. Estabelece, então, a partir da consecutio temporum, ou concordância dos tempos, dois grupos de tempos e os relaciona a dois mundos que designam os conteúdos possíveis de uma comunicação linguística: o mundo narrado, em que estaria assinalada uma atitude de "relaxamento", no sentido de menos comprometimento, por parte do locutor, perante o que está sendo relatado; e o mundo comentado, em que a atitude diante do que está sendo enunciado seria mais "tensa", comprometida.

Bronckart (2003) inspira-se nas ideias desses dois autores, na esteira dos quais situa sua proposta de divisão de mundos discursivos. Através de um refinamento teórico que busca explicá-los com base nas operações psicológicas que os constituem e na descrição das unidades linguísticas dos tipos de discurso que os traduzem, divide-os em quatro: mundo do expor autônomo (discurso teórico), mundo do expor implicado (discurso interativo), mundo do narrar autônomo (narração) e mundo do narrar implicado (relato interativo).

Para que cada um desses mundos seja codificado, as línguas naturais oferecem uma série de recursos, dentre os quais os sistemas de tempos verbais são o principal. Tais sistemas organizam-se, portanto, como uma ferramenta que possibilita aos interlocutores envolvidos em uma situação discursiva identificarem os mundos discursivos a partir dos quais produzem seus textos e neles se localizarem.

Cada um desses mundos apresenta suas próprias coordenadas espaçotemporais. Dessa maneira, os tempos verbais também podem ser analisados em uma dimensão que comporta a marcação 
de anterioridade, simultaneidade e posterioridade dos processos verbais em relação a pontos de referência. Reichenbach (1947) apresenta uma proposta de interpretação temporal das línguas naturais baseada na existência de três pontos teóricos na linha do tempo, que foi utilizada por Corôa (1985) para desenvolver uma simulação dos modos de expressão do tempo verbal em português. Essas propostas podem servir de base para uma análise da organização dos tempos verbais nessa dimensão, dentro de cada mundo discursivo. É justamente o que propomos neste trabalho: apresentar parâmetros, dentro da perspectiva dos mundos discursivos de Bronckart (2003) e das propostas de Reichenbach (1947) e Corôa (1985), a partir dos quais os tempos verbais possam ser analisados e definidos. $^{2}$

Para isso, dividimos o artigo em mais quatro seções: uma próxima, em que apresentamos os mundos discursivos e os tipos de discurso segundo Bronckart (2003); uma posterior, em que discutimos as propostas de Reichenbach (1947) e de Corôa (1985); uma outra, em que apresentamos os parâmetros para a definição dos tempos verbais, e uma última, em que contemplamos as conclusões do trabalho.

\section{OS MUNDOS DISCURSIVOS E OS TIPOS DE DISCURSO SEGUNDO BRONCKART (2003)}

Bronckart (2003, p. 149) distingue três níveis de abordagem da situação de interação verbal: o das atividades de linguagem, desenvolvidas no quadro de formações sócio-discursivas, e de que participam agentes singulares, que sediam ações de linguagem particulares; o dos textos, "como formas comunicativas globais e 'finitas' constituindo os produtos concretos das ações de linguagem, que se distribuem em gêneros adaptados às necessidades das formações sócio-discursivas" (BRONCKART, 2003, p. 149); e o dos tipos de discurso,

[...] como formas lingüísticas que são identificáveis nos textos e que traduzem a criação de mundos discursivos especificos, sendo esses tipos articulados entre si por mecanismos de textualização e por mecanismos enunciativos que conferem ao todo textual sua coerência seqüencial e configuracional (BRONCKART, 2003, p. 149).

Os mecanismos de textualização e os mecanismos enunciativos juntamente com a infraestrutura textual, entendida como o nível profundo da arquitetura interna dos textos, são os três níveis superpostos e em parte interativos que compõem o folhado textual (BRONCKART, 2003).

Os tipos de discurso são um dos elementos da infraestrutura textual. Também compõe essa infraestrutura, o plano geral do texto, que pode assumir formas muito variadas porque depende do gênero a que o texto pertence e de diversos fatores que conferem a este sua singularidade (extensão, condições externas de produção etc.). Além do mais, o plano geral do texto resulta de combinações dos tipos de discurso e das formas de planificação do texto, ${ }^{3}$ o que aumenta sua complexidade. As formas de planificação dizem respeito à outra dimensão da infraestrutura textual: a da organização sequencial ou linear do conteúdo temático.

\footnotetext{
${ }^{2}$ Essa proposta teórica foi desenvolvida e testada em tese de doutorado no Programa de Pós-graduação em Linguística da Universidade Federal do Ceará - UFC. Para mais detalhes, consultar Alves (2011).

${ }^{3}$ Adam (1992) apresenta como formas de planificação cinco tipos de sequências: narrativa, descritiva, argumentativa, explicativa e dialogal, dando, inclusive, a estas, primazia na infraestrutura do texto, que é definido a partir da combinação dos tipos de sequência nele presentes.
} 
Os tipos de discurso associados aos diferentes mundos discursivos constituem os elementos centrais na proposta de Bronckart e são abordados como arquétipos psicológicos e como tipos linguísticos.

\subsection{OS TIPOS DE DISCURSO COMO ARQUÉTIPOS PSICOLÓGICOS}

Os arquétipos psicológicos correspondem aos tipos de discurso vistos a partir da perspectiva das operações psicológicas que os constituem, sem codificação por meio dos recursos linguísticos de uma língua natural específica. Tais operações são de duas ordens e possibilitam a criação de quatro diferentes mundos discursivos que derivam em quatro arquétipos correspondentes.

Um primeiro tipo de operação psicológica diz respeito à relação entre as coordenadas gerais dos conteúdos mobilizados em um texto e as coordenadas do mundo ordinário em que se desenvolve a ação de linguagem da qual o texto se origina. Há duas possibilidades: a primeira é a de que a relação entre as coordenadas seja explicitada como disjunta, de forma que as coordenadas gerais dos conteúdos mobilizados em um texto, possam ser estabelecidas sem referência às coordenadas do mundo ordinário em que se desenvolve a ação de linguagem. A organização dos conteúdos do texto será feita com base em uma origem espaçotemporal, a partir da qual se constrói todo um eixo de referência. Essa origem espaçotemporal pode ser absoluta, independente e completamente indiferente à duração associada ao ato de produção, ou pode ser dêitica, independente, mas calculável a partir da duração associada ao ato de produção. Os fatos constantes do texto, portanto, não são apresentados como acessíveis no mundo ordinário, são narrados como se tivessem se dado em outro lugar e em outro tempo. Os mundos discursivos assim criados constituem os mundos do narrar.

A segunda possibilidade é a de que não haja explicitação quanto à disjunção das coordenadas. Dessa forma, as coordenadas gerais dos conteúdos mobilizados em um texto não poderão ser construídas sem referência às coordenadas gerais do mundo ordinário. A organização dos conteúdos do texto será feita a partir de um eixo de referência que não terá como base uma origem espaçotemporal, podendo ancorar-se na própria duração do ato de produção. Embora o mundo discursivo criado seja outro em relação ao mundo ordinário, aquele é constituído com base nas relações espaço-temporais deste: o passado, o presente e o futuro terão como base o passado, o presente e o futuro do mundo ordinário. As coordenadas do mundo discursivo são conjuntas às coordenadas do mundo ordinário. Os fatos constantes do texto, portanto, são apresentados como acessíveis no mundo ordinário, não são narrados, mas mostrados, expostos. Os mundos discursivos assim criados constituem os mundos do expor.

O segundo tipo de operação psicológica diz respeito à relação das instâncias de agentividade de um texto, nele situadas espaçotemporalmente - em outras palavras, dos personagens, grupos sociais etc. mobilizados em um texto e seu contexto espaço-temporal -, com os parâmetros físicos da ação de linguagem que se desenrola no mundo ordinário, isto é, com agente-produtor, interlocutor e o eixo de referência espaçotemporal da própria produção.

Também há duas possibilidades: uma delas é a de que a relação das instâncias de agentividade e sua inscrição temporal com os parâmetros físicos da ação de linguagem seja explicitada, de forma que se estabeleça uma interdependência entre essas instâncias e os parâmetros físicos. $\mathrm{O}$ texto implica os parâmetros físicos da ação de linguagem: as instâncias de agentividade nele mobilizadas só são identificadas com referências dêiticas a esses parâmetros. Ele só pode ser completamente interpretado se houver acesso às suas condições de produção. 
A outra possibilidade é a de que haja uma autonomia das instâncias de agentividade e de sua inscrição espaçotemporal em relação aos parâmetros físicos da ação de linguagem. O texto, por conseguinte, não implica esses parâmetros e para sua interpretação não é necessário conhecimento das condições de produção.

Dessa maneira, tanto os mundos do narrar, quanto os mundos do expor podem ser apresentados como implicados ou como autônomos, do que derivam quatro mundos, conforme o quadro com entrada dupla reproduzido abaixo:

Quadro 1 - Mundos discursivos conforme Bronckart Coordenadas gerais dos mundos

\begin{tabular}{cccc} 
& & Conjunção & Disjunção \\
& & EXPOR & NARRAR \\
\cline { 2 - 3 } Relação ao ato & Implicação & Discurso Interativo & Relato Interativo \\
\cline { 2 - 3 } de produção & Autonomia & Discurso Teórico & Narração \\
\cline { 2 - 3 } & \multicolumn{2}{c}{ Fonte: Bronckart (2003, p. 157) }
\end{tabular}

Cada um desses arquétipos psicológicos é atualizável nos textos através de conjuntos de unidades linguísticas disponíveis nas línguas naturais. Quando se busca descrevê-los a partir da identificação das unidades de uma determinada língua que se atualizam mais regularmente em cada um deles, os tipos de discurso deixam de ser vistos como arquétipos psicológicos para ser vistos como tipos linguísticos.

\subsection{OS TIPOS DE DISCURSO COMO TIPOS LINGUÍSTICOS}

São vários os tipos de unidades linguísticas que, por sua ocorrência mais ou menos regular, podem caracterizar cada um dos tipos de discurso. Os subsistemas temporais, contudo, têm um papel crucial nessa caracterização e é o que interessará mais de perto neste artigo. Bronckart (2003) procede à descrição dos conjuntos de unidades que ocorrerem regularmente em cada tipo de discurso, no francês.

No discurso interativo, ocorrem unidades que se referem à situação de interação verbal e que marcam a implicação dos parâmetros físicos no mundo discursivo criado. A interação, oral ou escrita, fica explícita pelos turnos de fala nas situações dialogadas e pela presença de frases não declarativas. A implicação dos parâmetros físicos fica explícita pela ocorrência de unidades que se referem a objetos acessíveis, aos interlocutores e ao espaço-tempo da interação, como dêiticos espaciais e temporais; pela ocorrência de nomes próprios, pronomes e adjetivos de primeira e segunda pessoa do singular e do plural referentes aos interlocutores, com valor exofórico, e formas verbais de primeira e segunda pessoa. Ocorrem, ainda, mais ou menos regularmente, outras unidades com valor discriminativo mais fraco em relação ao tipo de discurso, como anáforas pronominais (em oposição às nominais) e auxiliares com valor modal e pragmático como poder dever e querer. O discurso interativo é caracterizado também por uma alta densidade verbal (verbos por palavra) e muito baixa densidade sintagmática.

A implicação, no discurso interativo, é também marcada pela ocorrência de um subsistema de tempos que tem o presente e o passado composto como centrais, aos quais se junta a forma de 
futuro perifrástico com aller + infinitivo. ${ }^{4}$ No discurso interativo, os tempos verbais têm um caráter acentuadamente dêitico, pois o eixo de referência global em que são localizados tem a duração associada ao ato de produção como centro.

O discurso teórico, que ocorre, principalmente, em situações monologadas escritas, é caracterizado inicialmente pela ausência de frases não declarativas. A autonomia das instâncias de agentividade e da sua inscrição espaçotemporal em relação aos parâmetros físicos é marcada: pela ausência de unidades que remetem aos interlocutores ou ao espaço-tempo da interação; pela não ocorrência de nomes próprios, de pronomes e adjetivos de primeira e segunda pessoa do singular com valor exofórico e de formas verbais de primeira e segunda pessoa do singular. A autonomia é marcada, também, em conjunto com essas características principais: pela presença de organizadores com valor lógico-argumentativo, como por outro lado, de fato, mas etc.; pela ocorrência de modalizações lógicas e, sobretudo, do auxiliar modal poder; pela presença de procedimentos de focalização de segmentos textuais e de referência a outras partes do texto ou ao intertexto científico; pela grande ocorrência de frases passivas; pela ocorrência frequente de anáforas pronominais e nominais e de procedimentos de referenciação dêitica intratextual; por uma baixa densidade verbal e por uma muito alta densidade sintagmática.

O subsistema temporal que ocorre no discurso teórico é semelhante ao que ocorre no discurso interativo, mas com uma nítida dominância do presente em relação ao passado composto e com muito poucas ocorrências de futuro, sendo que o valor desses tempos é agora genérico, diferente do valor mais dêitico que têm no discurso interativo. Isso decorre da não ancoragem do eixo de referência temporal global no ato de produção e da não explicitação de uma origem para esse eixo temporal. Os eventos expostos passam a ter validade ilimitada. Há, ainda, ocorrência de formas do condicional no discurso teórico.

O relato interativo é próprio de situações de interação geralmente monologadas, orais reais ou postas em cena em trechos de gêneros escritos, e caracteriza-se, a princípio, por ausência de frases não declarativas. Nesse tipo de discurso disjunto, a implicação dos parâmetros físicos da ação de linguagem é estabelecida: pela ocorrência de organizadores temporais que servem como traços de escansão da atividade narrativa iniciada a partir da origem espaçotemporal; pela ocorrência de pronomes e adjetivos de primeira e segunda pessoa do singular e do plural, que se referem aos interlocutores da situação de interação em que o relato foi desenvolvido; pela ocorrência dominante de anáforas pronominais em relação às nominais, que geralmente se apresentam na forma de repetição fiel do sintagma antecedente; por uma alta densidade verbal e por uma baixa densidade nominal, como acontece no discurso interativo.

A implicação, no relato interativo, também é marcada pela utilização de um subsistema temporal que tem o imperfeito e o passado composto como tempos centrais, juntos com o mais-que-perfeito e o condicional.

Na narração, tipo de discurso geralmente monologado e próprio de gêneros escritos, há presença apenas de frases declarativas. A autonomia das instâncias de agentividade em relação aos parâmetros físicos da ação de linguagem é caracterizada: pela presença de organizadores temporais; pela ausência de pronomes e adjetivos de primeira e segunda pessoa do singular e do plural que se referem ao produtor do texto ou destinatário; pela ocorrência conjunta de anáforas pronominais e nominais (sendo

\footnotetext{
${ }^{4}$ Relativamente ao português, como não há um passado composto com valor temporal semelhante ao do francês, seu papel acaba sendo assumido pelo pretérito perfeito simples do indicativo. A função da forma de futuro perifrástica pode ser assumida não só pela forma perifrástica correspondente em português, ir + infinitivo, mas por outras formas de expressão de futuridade como o próprio presente simples do indicativo e o futuro do presente do indicativo.
} 
que estas últimas retomam, geralmente, o sintagma nominal por substituição lexical), e por densidades verbal e sintagmática medianas em relação aos outros tipos de discurso.

A autonomia, na narração, é caracterizada especialmente pela utilização de um subsistema temporal que tem como tempos centrais o pretérito simples e o imperfeito, aos quais se associam o passado anterior, o mais-que-perfeito, o condicional e formas com o auxiliar no imperfeito + infinitivo.

É claro que as configurações de unidades dos tipos linguísticos descritas acima são relativas ao francês. De antemão, já pode ser apontada, em relação ao português, uma grande diferença, no que diz respeito à configuração dos subsistemas temporais, que é a inexistência, nessa língua, de um passado composto nos moldes do passado composto francês. Consequentemente, como o passado composto ocupa o lugar de tempo central em certos tipos de discurso, os subsistemas temporais no português terão uma organização razoavelmente diferente.

No francês, entre os subsistemas temporais dos tipos de discurso do mundo do narrar, uma das diferenças mais importantes é justamente a oposição passado simples X passado composto. No português, essa diferença fica anulada, uma vez que o pretérito perfeito assumirá a função dos dois tempos. Outra consequência é a de que o pretérito perfeito terá, no português, um duplo papel a cumprir: tanto poderá ser um tempo do mundo do narrar, de que é próprio no francês, como do mundo do expor, já que nesse mundo ocupará o lugar do passado composto francês.

Apesar dessas diferenças, os tempos verbais em português respondem também às diferenças nessa dimensão dos mundos discursivos. Koch $(1984,1989,1992)$ identifica grupos temporais no português a partir da proposta de Weinrich (1974), cujos grupos de tempo são bastante semelhantes aos subsistemas temporais apontados por Bronckart, e os associa também aos mundos discursivos. O trabalho de Machado (1995) também confirma a relação entre subsistemas temporais e os tipos de discurso no português.

Além de observados quanto a suas funções na dimensão dos mundos discursivos, os tempos verbais podem ser analisados quanto a suas funções em uma dimensão mais específica, interior a cada mundo discursivo: a dimensão que comporta as marcações de anterioridade, simultaneidade e posterioridade dos processos expressos pelos verbos em relação a pontos de referência, relacionados ou não à duração do ato de produção.

Weinrich (1974, p. 349-350) denomina essa dimensão de dimensão da perspectiva comunicativa, que compõe as três dimensões fundamentais a partir das quais o sistema temporal do verbo deve ser analisado, ao lado da dimensão da atitude comunicativa, correspondente à dos mundos discursivos, e da dimensão do relevo, ${ }^{5}$ que é relativa aos efeitos da distinção aspectual perfectivo/imperfectivo, embora Weinrich tenha outra interpretação, por rejeitar a noção de aspecto. A dimensão da perspectiva comunicativa é um dos únicos pontos em que o autor reconhece a influência do tempo cronológico, que tenta a todo custo excluir da explicação dos sistemas temporais. Na verdade, como pondera Abreu (1998, p. 28), a perspectiva dos tempos verbais a partir dos mundos discursivos não é incompatível com as perspectivas mais referenciais dos tempos.

Entendemos, portanto, que cada tipo de discurso atualizador de um mundo discursivo apresenta seu subsistema temporal, composto de tempos verbais que expressam anterioridade, simultaneidade e posterioridade, em outras palavras, passado, presente e futuro. Um ponto central é, então, definir anterioridade, simultaneidade e posterioridade na dimensão da perspectiva comunicativa.

\footnotetext{
${ }^{5}$ A dimensão de relevo, que diz respeito às distinções aspectuais, traduz-se, na perspectiva de Bronckart (2003), em duas de quatro funções de coerência verbal, às quais faremos remissão a seguir. Essas funções relativas a valores aspectuais não são definidas com base nos parâmetros que são nosso foco, portanto, não são exploradas neste trabalho.
} 


\section{REICHENBACH E OS TRÊS PONTOS TEÓRICOS NA LINHA DO TEMPO}

Para definir anterioridade, simultaneidade e posterioridade, recorremos, primeiramente, a Reichenbach (1947), lógico que formalizou uma interpretação temporal das línguas naturais. Um ponto fundamental para entender a sua teoria é a consideração de como o próprio tempo pode ser definido. Há três tipos de teorias pelas quais se pode fazê-lo: as do tempo absoluto, para as quais o tempo tem existência independente dos eventos e flui sem relação com qualquer coisa externa a ele; as de tempo relacional, para o qual não existe uma entidade tempo, o qual somente é constituído a partir dos eventos e de suas relações; e as de tempo relativo (das quais a mais conhecida é a de Albert Einstein), para as quais as relações temporais entre percepções de eventos podem não corresponder às relações temporais entre eventos, ou seja, o tempo só pode ser definido relativamente a um observador, de cuja posição dependerá a simultaneidade ou a sucessividade dos eventos. É na teoria da relatividade de Einstein que se baseia a interpretação de Reichenbach.

Para formalizar sua interpretação, Reichenbach estabeleceu três pontos teóricos na linha do tempo: o momento do evento $(M E)$, aquele em que ocorre o evento a que o enunciado se refere, ou seja, o tempo da predicação; o momento da fala $(M F)$, o tempo da comunicação, isto é, o momento em que a enunciação sobre um dado evento se realiza; e o momento de referência (MR), eixo temporal fixo de referência, com relação ao qual são localizados tanto o momento da fala, quanto o momento do evento, e a partir do qual se define simultaneidade e anterioridade; é o tempo da referência. Embora esses três pontos sejam construtos teóricos, o momento de referência é o mais abstrato de todos e sua inclusão na interpretação de Reinchenbach é uma consequência direta da visão relativista do tempo: só se pode proceder a uma interpretação temporal a partir de um sistema de referência, pois o tempo não existe como entidade absoluta.

A percepção dos eventos não será única, mas dependerá do ponto de vista, ou de referência adotado. Presente, passado e futuro não podem ser definidos absolutamente, já que agora um evento que é presente, passado ou futuro quando observado de um determinado ponto de referência, pode não o ser, de outro.

Corôa (1985), a partir da teoria de Reichenbach, desenvolve uma simulação formal dos modos de expressão da categoria de tempo em português. É com base nas relações de anterioridade e simultaneidade entre os três pontos temporais de Reichenbach que os tempora ${ }^{6}$ das línguas naturais podem ser estudados e delimitados. As combinações matematicamente possíveis nunca estão presentes todas de uma vez em uma língua, que faz uma seleção das possibilidades no seu desenvolvimento histórico, organizando-as em sistemas.

No português, o presente é definido como tempus em que ME, MF e MR são simultâneos (ME,MF,MR) ${ }^{7}$ Essa simultaneidade só é percebida quando se consideram ME, MF e MR não como momentos únicos e indivisos, mas como conjuntos de momentos. Dessa forma, para que haja a simultaneidade entre os três momentos, eles não precisam coincidir quanto aos seus limites: é necessário tão somente que um ponto de cada um dos três coincida. Podem ser, na verdade, parcialmente simultâneos, mas quanto menos pontos entre os três coincidirem, mais fraca é a força dêitica do tempo expresso.

As formas do pretérito são as que mais diretamente se relacionam com o ME. Traduzem fatos mais reais e um mundo mais objetivo, uma vez que se referem a eventos já acontecidos.

\footnotetext{
${ }^{6} \mathrm{~A}$ autora faz uma distinção terminológica entre tempo, que usará para se referir ao conceito de tempo que faz parte de nossa consciência, e tempus (plural tempora), para as formas gramaticais que o expressam.

7 Vírgulas entre os momentos nessas representações indicam simultaneidade, e travessões, anterioridade.
} 
Nelas, o ME ocorre sempre antes do MF. Dentre as possibilidades matemáticas, o português seleciona ME-MR-MF, que representaria o pretérito mais-que-perfeito, ME-MR,MF, o pretérito perfeito, e ME,MR-MF, o pretérito imperfeito.

Já nas formas do futuro, o ME está sempre precedido por MF. As possibilidades em português são: MF,MR-ME; MR-MF-ME e MF-ME-MR. A representação MF, MR-ME corresponderia ao futuro do presente do português, como na oração "O garoto virá mais cedo" (CORÔA, 1985, p. 58). Há certas semelhanças entre futuro e perfeito: o evento tem lugar num tempo necessariamente diferente do momento da fala, só que em um tempo que virá e não que já foi, tomado de uma perspectiva do MF. Também se percebe que o MF e o MR são simultâneos, só que em vez de se fazer referência a um evento totalmente acabado, faz-se referência a um momento totalmente não começado.

A representação MR-MF-ME retrata o futuro do pretérito do português, como na oração " $\mathrm{O}$ garoto viria mais cedo" (CORÔA, 1985, p. 58). Segundo Corôa, tentando-se excluir as interpretações modais e hipotéticas, constata-se que o evento ainda não ocorrido já era previsto em um tempo anterior ao da enunciação. No chamado futuro histórico, como na frase "Na manjedoura, nascia (nasceu) aquele que seria (viria a ser) o salvador do mundo" (CORÔA, 1986, p. 60), essas relações ficariam bem evidentes: o falante compreende que o evento "ser o salvador do mundo" é futuro somente em relação a um passado e o faz tomando como base um ponto de referência anterior ao momento da fala.

A representação MF-ME-MR ocorre também em português, mas com uma forma analítica, como na frase "Telefone-me amanhã que já terei lido sua proposta". O evento "telefonar", MR para o evento "ler sua proposta", é posterior ao evento no futuro.

Embora apoiadas na perspectiva de Reichenbach (1947), da qual também fazemos uso, essas definições dos tempos verbais apresentam alguns problemas do ponto de vista que estamos adotando. Percebemos que os três momentos são colocados e relacionados em uma linha temporal a partir da qual se obtém um sistema temporal único, em que se opõem todas as formas verbais. Observando as delimitações dos tempos do futuro, por exemplo, vemos que futuro do presente e futuro do pretérito têm de ter, nessa análise de Corôa, representações diferentes, assim como o futuro do presente composto.

Contudo, chama atenção o fato de o futuro do pretérito composto (por exemplo, "teria ficado" em "Joana teria ficado mais feliz se você tivesse vindo") não ter representação. É certo que Corôa (1985, p. 58) tenta se ater, ao máximo, aos empregos menos modais e mais temporais do futuro, mas isso não explica a falta de referência ao futuro do pretérito composto, já que ela procurou delimitar o futuro do pretérito simples, nem mais nem menos rico em relação a valores modais.

Questionamos, também, e isso dentro da proposta que desenvolvemos é ainda mais importante, a própria representação MR-MF-ME como explicativa do futuro do pretérito português. Ora, considerando, como o faz Corôa (1985), um único sistema temporal em que se posicionam numa linha um ME, um MR e um MF, do que se pode chegar à definição de todos os tempos, não vemos como justificar, no próprio exemplo que usa, o evento "seria o salvador do mundo" como posterior ao momento da fala. Em sua explicação sobre o exemplo acima, ela afirma que o momento do evento é posterior a um momento de referência anterior ao momento da fala, mas nada diz em relação ao posicionamento do momento do evento relativamente ao momento da fala: "O evento "ser o salvador do mundo" é futuro apenas a partir de uma perspectiva passada - hoje em dia seria presente ou passado. O falante e o ouvinte contemplam essa possibilidade a partir de um sistema de referência que se colocou antes da enunciação de (54)" [Na manjedoura, nascia (nasceu) aquele que seria (viria a ser) o salvador do mundo] (CORÔA, 1985, p. 60). Fica bem claro que ME é posterior a um MR anterior a MF, mas nada fica dito de ME em relação a MF. Isso se dá por uma 
única e muito importante razão: MF, exatamente como o momento da enunciação no mundo ordinário do agente produtor, em que se localiza também o ouvinte, não influi em exemplos como esse. Dessa forma, mesmo MR não pode ser definido como anterior em relação a esse MF.

Entendemos que os pontos teóricos de Reichenbach (1947), numa análise das formas verbais e de suas funções em uma língua, devem ser considerados de uma perspectiva mais ampla, que leve em conta a dimensão dos tipos de discurso tradutores dos diferentes mundos discursivos. Chegamos, então, à nossa tese central: postulamos que a constituição desses pontos depende das características dos tipos de discurso. Dessa forma, as funções temporais devem ser analisadas e definidas a partir da consideração de que os tempos verbais então organizados não em um sistema temporal único, mas em subsistemas característicos de cada tipo de discurso.

Cada tipo de discurso teria sua própria linha temporal em que os pontos teóricos se localizam em termos de simultaneidade, anterioridade e posterioridade, que não se sobreporia à linha temporal de outro tipo de discurso. Em linhas gerais, as relações de anterioridade, simultaneidade e posterioridade entre os pontos teóricos seriam as mesmas; a diferença residiria no estatuto desses pontos em cada tipo de discurso.

As línguas são sensíveis a isso, traduzindo essa diferença com diferentes conjuntos de formas verbais organizados em subsistemas temporais. Por isso, temos, por exemplo, futuro do presente e futuro do pretérito; não é, porém, que se trate de dois "futuros" diferentes que podem ser opostos entre si em uma mesma linha temporal: remetem à posterioridade, a mesma, mas em diferentes tipos de discurso tradutores de diferentes mundos discursivos.

Ressalte-se, contudo, que os tempos verbais desses subsistemas não são exclusivos de um determinado tipo de discurso, numa relação isomórfica, de um-para-um. Muitas vezes, tempos verbais característicos de um tipo de discurso podem ocorrer em outro. No entanto, essas ocorrências causam efeitos no tipo de discurso em que a forma verbal aparece deslocada, levando, para este, aspectos semântico-discursivos próprios do tipo de discurso de que são características. Weinrich (1974, p. 139) explica tais ocorrências a partir da noção de metáfora temporal: por causa do deslocamento, a forma verbal adquire valores metafóricos que são decorrentes da tensão entre seu valor original e o valor que passa a ter no novo contexto. De maneira semelhante, Bronckart (2003) explica, por exemplo, o uso de formas do presente do indicativo como o tempo de perspectiva de presente em um texto do mundo do narrar (e dos outros tempos, pretérito perfeito e futuro do presente, como os tempos de perspectiva de passado e futuro, respectivamente), que teria o intuito de trazer, para o texto do narrar, a característica dos textos do expor de maior envolvimento com os eventos enunciados. Isso produz, no interlocutor, o efeito da hipotipose (BRONCKART, 2003, p. 200), a sensação de que os fatos se desenrolam diante de si, embora tenham se dado em "outro mundo".

\section{UMA PROPOSTA DE PARÂMETROS DE LOCALIZAÇÃO TEMPORAL BASEADA NOS TIPOS DE DISCURSO}

Bronckart (2003), na análise dos mecanismos de textualização e coesão verbal, também faz uso das proposições de Reichenbach (1947). Critica as abordagens-padrão do tempo que definem os valores de temporalidade tendo em vista as relações entre o momento da fala e o momento do processo verbal. Presente, passado e futuro são definidos, assim, respectivamente, a partir da simultaneidade, anterioridade e posterioridade do segundo momento relativamente ao primeiro. A crítica de Bronckart (2003) reside no fato de essas abordagens serem fisicalistas, pois tomam esses momentos como objetáveis fisicamente no mundo ordinário, e binárias, dado que se baseiam exclusivamente na existência desses dois momentos. 
$\mathrm{O}$ autor argumenta que um terceiro momento, o momento de referência de Reichenbach (1947), é fundamental na descrição das funções temporais das formas verbais. Além disso, os momentos não seriam diretamente objetáveis, teriam um caráter psicológico. Através da postulação desses três momentos, seriam melhor explicadas, por exemplo, as diferenças entre as frases "Amanhã, Pedro vai a Lausanne" e "Amanhã, Pedro irá a Lausanne" (BRONCKART, 2003, p. 276). A forma verbal no presente ou no futuro seria explicada em termos da codificação de diferentes percepções das relações entre os três momentos: a primeira resultaria da codificação de uma relação de inclusão de ME em MR, e a segunda, da codificação de uma relação de posterioridade de ME em relação a MF.

Para adequá-los à sua perspectiva textual, Bronckart (2003, p. 181) redimensiona MF, MR e ME, que passam a ser chamados, respectivamente: duração de produção, que remete à duração psicologicamente construída de qualquer produção discursiva, podendo levar um segundo, no caso da tomada de fala, ou anos, no caso da produção de um romance, por exemplo; eixo de referência temporal, duração formal ou psicológica em que se desenvolve o processo narrativo e o processo expositivo; e processo, referente aos conteúdos expressos pelos verbos, tanto os que podem ser objetivamente datados, como os fictícios ou hipotéticos. ${ }^{8}$ Esses três parâmetros são a base de duas das quatro funções de coesão verbal: a temporalidade primária e a temporalidade secundária ${ }^{9}$ :

Na função de temporalidade primária, o processo é diretamente relacionado ou com um dos eixos de referência, ou com a duração associada ao ato de produção. Em termos culiolianos, essa função estabelece um modo determinado de localização do processo em relação a um dos parâmetros de controle. Quando esse parâmetro é a duração associada ao ato de produção, distinguiremos localizações de anterioridade, simultaneidade e posterioridade; quando esse parâmetro é o eixo de referência global de um tipo de discurso, distinguiremos localizações neutras, assim como localizações isocrônicas, retroativas e projetivas; quando se trata de um eixo de referência local, identificaremos, finalmente, uma localização de inclusão.

A função de temporalidade secundária consiste em situar um processo em relação a outro processo, que é, por sua vez, relacionado com um dos parâmetros de controle. (BRONCKART, 2003, p. 283)

A distinção entre a função de temporalidade primária e a de temporalidade secundária reside, pois, na relação direta do processo relativamente a um dos parâmetros de controle, no caso das primeiras, e na relação indireta, mediada por outro processo, no caso das segundas. ${ }^{10}$

Nesse ponto, levantamos alguns problemas e pretendemos desenvolver uma proposta algo diferente da de Bronckart (2003). Repare-se que, nessa forma de explicar, uma forma de presente

\footnotetext{
8 Os tipos de discurso, como temos visto, revelam a construção de mundos discursivos específicos. Os tipos de discurso são regidos pelo narrador e pelo expositor, "instâncias teóricas às quais o agente produtor atribui 'a responsabilidade do dizer' e sob a égide dos quais se desenvolvem, respectivamente, o processo narrativo e o processo expositivo" (BRONCKART, 2003, p. 281). As noções de narrador e expositor, englobadas pela denominação de textualizador (BRONCKART, 2003, p. 96), correspondem à noção de enunciador tal como introduzida por Ducrot (1984) para dar conta das diferentes vozes (polifonia) que se expressam em um texto. $O$ processo narrativo e o expositivo constituem, portanto, o encadeamento dos processos, apresentados por essas instâncias teóricas, para compor o texto narrativo e o expositivo.

${ }^{9}$ As outras duas funções de coerência verbal, baseadas em distinções aspectuais, são: contraste global, em que uma série de processos é colocada em primeiro plano em relação a outras; e contraste local, em que um processo é colocado em primeiro plano em relação a outro, localmente. Tais distinções traduzem a forma de Bronckart (2003) incluir o aspecto verbal em sua perspectiva.

${ }^{10}$ Essa noção de temporalidade secundária se aproxima do que Comrie (1985) chama de tempo relativo-absoluto, e Fleischman (1982) chama de tempo relativo, em que a localização de uma situação não é definida a partir do presente do momento da fala, mas a partir de um momento de referência fornecido pelo contexto linguístico.
} 
do indicativo, como no exemplo acima (“Amanhã, Pedro vai a Lausanne”) não poderia ser considerada como uma variante que expressa futuridade, por exemplo, como o é em muitos estudos (cf. OLIVEIRA, 2006; ALVES, 2011), uma vez que resultaria, nos termos de Bronckart (2003), da codificação de uma relação específica entre somente dois dos parâmetros, com o que, de antemão, não concordamos.

Em nossa visão, tal forma de explicar as funções temporais continua sendo binária. Na codificação de cada relação, só entram dois termos como está dito na citação acima: o processo ou é situado em relação ao eixo de referência temporal, do que resultou o presente, em uma das frases do exemplo acima, ou à duração de produção, do que resultou o futuro, na outra frase. Preferimos considerar alternativamente que, tanto num como no outro caso, a forma verbal codifica a mesma função de localização do processo. Pretendemos assumir que os mesmos parâmetros entram em jogo nos dois casos, o que nos permitiria analisar as duas formas verbais como variantes codificadoras de uma mesma função, a de expressão de futuro, como têm sido consideradas em vários estudos, como os mencionados acima. Mas, para isso, é necessário um rearranjo na proposta de Bronckart (2003).

De acordo com tal proposta, nos mundos do expor, a função de temporalidade primária é estabelecida tendo como base a localização do processo ou relativamente à duração associada ao ato de produção, do que resultam localizações de anterioridade, simultaneidade e posterioridade, ou relativamente a eixos de referência, que podem ser ilimitados e atemporais, do que resultam localizações neutras (principalmente no discurso teórico) e também podem ser locais, delimitados por advérbios e outras expressões temporais, do que decorrem localizações isocrônicas e heterocrônicas (retroativas ou projetivas) ou de inclusão, como no exemplo "Amanhã, Pedro vai a Lausanne".

Nos mundos do narrar, a função de temporalidade primária é estabelecida tendo em vista a localização do processo somente em termos do eixo de referência temporal, cujo início é marcado pela origem espaçotemporal. Os processos podem, então, ser narrados pari passu com o desenvolvimento desse eixo, do que decorrem localizações isocrônicas, ou sem sincronia em relação a esse eixo, do que resultam localizações heterocrônicas (retroativas ou projetivas). A duração associada ao ato de produção não tem pertinência na localização dos processos. ${ }^{11}$

Talvez se possa sustentar um ponto de vista diferente: o de que a função de temporalidade primária é sempre estabelecida com base em três parâmetros de localização (no mínimo): o processo (parâmetro que será adotado por nós nos moldes propostos por Bronckart) é sempre situado em relação a um eixo de referência temporal global e a um ponto de referência identificado como a fase atual do processo de textualização (fase atual do processo expositivo ou fase atual do processo narrativo). ${ }^{12}$

Conforme já comentamos, Bronckart (2003) redimensiona, em sua perspectiva textual, o momento de referência (MR) de Reichenbach (1947) e passa a chamá-lo de eixo de referência temporal de um tipo de discurso, que corresponde à duração formal ou psicológica do processo narrativo ou do processo expositivo. Seria, portanto, um eixo de referência global que ajuda a

\footnotetext{
${ }^{11}$ Esse fato também é afirmado, por exemplo, em Reinhart (1984). Segundo a autora (REINHART, 1984, p. 786), o fato de as sequências narrativas não serem tomadas a partir do momento da fala é uma de suas características centrais. Nelas, o tempo da fala é irrelevante e o mundo temporal do texto é construído internamente. Tem seu próprio "presente narrativo", a partir de que os eventos são avaliados.

${ }^{12}$ Estamos usando o termo especificador "de textualização" para subsumir, numa designação mais geral, os termos expositivo e narrativo. Como as instâncias formais, expositor e narrador, são chamadas de textualizadores (BRONCKART, 2003, p. 95-96), são responsáveis por textualizar, ou seja, desenvolver os processos expositivo e narrativo. Vemos, então, a possibilidade de usar o termo especificador "de textualização" para nos referirmos de forma geral aos processos expositivo e narrativo.
} 
definir o próprio tipo de discurso. Entretanto, Bronckart (2003) também menciona a possibilidade de esse eixo global coexistir com eixos de referência locais, mas não se aprofunda em como essa coexistência se efetiva. Fica dito apenas que tais eixos podem ser tomados para a definição de uma localização de inclusão do processo.

Esses eixos de referência temporal locais parecem ter, na verdade, uma função mais geral de especificar a localização de determinado processo em relação ao eixo de referência global, ressaltando as relações de anterioridade, simultaneidade ou posterioridade, como o fazem advérbios e expressões adverbiais, a exemplo de amanhã, ontem, na semana passada. Outros, no entanto, para além de especificar, chegam a limitar a temporalidade do processo, colocando-o como dependente de outro processo não acontecido, como o fazem orações temporais e condicionais como quando ele chegar, se ele vier, se ele tivesse vindo. Esse tipo de eixo local parece interferir na relação entre o processo e os outros parâmetros: ocorre a atuação simultânea de dois momentos de referência na localização do evento: o eixo de referência temporal global situa a temporalidade do evento e estabelece o mundo discursivo, e o eixo de referência temporal local, constituído de um processo não acontecido, limita essa temporalidade. Por exemplo, essa limitação parece estar na base da distinção entre um futuro mais temporal e outro mais modal (cf. CAMARA JR, 1994, p. 101). O eixo de referência limitador diminui a força dêitica da forma verbal e acentua as perspectivas modais de irrealidade, possibilidade e probabilidade.

O que chamamos de fase atual do processo de textualização (fase atual do processo expositivo ou fase atual do processo narrativo) se refere a um ponto de referência que o expositor ou o narrador toma como centro do eixo de referência temporal global para apresentar um processo como simultâneo, anterior ou posterior a ele. Esse centro ou pode ser a duração associada ao ato de produção, como postulada por Bronckart, e nesse caso será fixo, permanecendo como centro em todo o processo de textualização; ou pode ser um outro processo, quando a duração de produção não tiver pertinência, e, nesse caso, será momentâneo, podendo ser substituído adiante, no decorrer do processo de textualização.

$\mathrm{Na}$ verdade, nas próprias explicações de Bronckart, está pressuposto esse parâmetro, mas não nos moldes em que o estamos desenvolvendo. Para explicar esse parâmetro que estamos propondo e mostrar em que se diferencia do que Bronckart (2003) propõe, reproduzimos abaixo o mesmo exemplo de texto narrativo em que se baseia:

Robert passou (L.iso) às margens do Rhône duas semanas encantadoras. Pois Avignon para onde todo o ouro da Cristandade afluía (L.iso), era (L.iso) uma cidade de prazer sem igual [...] O novo par de França teve várias audiências com o Santo Padre, um festim foi dado (L.iso) em sua honra no palácio pontifical e ele se entreteve (L.iso) doutamente com bom número de cardeais [...] De volta a Paris no mês de março, Robert esfregava (L.iso) as mãos e afirmava (L.iso) que de novo ia se produzir (L.pro).

No começo de maio, morreu (L.iso) o bravo Gaucher de Chatillon, na entrada de seu octagésimo ano. Ele tinha nascido (L.retro) sob o reinado de Saint Louis e tinha exercido (L. retro) durante vinte anos o cargo de 'connetáble'. Sua voz tinha várias vezes mudado (L. retro) a sorte das batalhas e prevalecido (L.retro) nos conselhos reais.

No dia 26 de maio, Eduardo III [...] embarcou (L.iso) em Douvres para vir prestar homenagem a seu primo de França [...]. Um soberano de dezesseis anos, confiado à guarda de dois bispos, ia então afrontar (L.pro) a mais impressionante corte do mundo [grifos do autor] (DRUON, 1970 apud BRONCKART, 2003, p. 286) 
Vejamos como o autor explica a organização da coesão verbal na narração a partir desse trecho:

Examinando esse trecho de narração, observamos, primeiramente, que nenhum dos tempos verbais que aparecem traduz uma relação dos processos com a duração de produção. Isso confirma a não-pertinência absoluta desse parâmetro externo.

Os tempos verbais observáveis, na verdade, marcam modalidades especificas de localização dos processos em relação ao eixo de referência constituído pelo decorrer do processo narrativo. Permanecendo no plano referencial, poderiamos admitir que os processos constitutivos da diegese (da história narrada) desenvolveram-se de acordo com uma ordem de sucessão $<<$ objetiva $>>$. Mas, na narração mesma, a apresentação [grifo nosso] desses processos não se efetua necessariamente reproduzindo, tal qual, esse ordenamento temporal verossímil. Em alguns casos, é certo, os processos são efetivamente apresentados [grifo nosso] em uma ordem que parece reproduzir a dos acontecimentos da diegese; consideraremos, então que o decorrer do processo narrativo e a ordem de sucessão dos processos se desenvolvem $<<$ em paralelo $>>$ e que esses processos são objetos de uma localização isocrônica (L.iso) em relação ao eixo de referência temporal. Mas, em outros casos, os processos são claramente apresentados [grifo nosso] em uma ordem deslocada em relação à da diegese: ou eles são apresentados [grifo nosso] como anteriores à fase atual do curso do processo narrativo [grifo nosso] e, então, são objetos de uma localização retroativa (L.retro), ou são apresentados [grifo nosso] como posteriores à fase atual desse processo [grifo nosso] e, então, são objeto de uma localização projetiva (L.pro) (BRONCKART, 2003, p. 286-287)

Em vários momentos da exposição, há referência ao fato de os processos serem apresentados, conforme grifamos. Se os processos são apresentados, são apresentados por alguma entidade, nesse caso, o narrador, que assume e gerencia a responsabilidade de dizer. Chama atenção a expressão fase atual do processo narrativo. Essa atualidade tem de ser definida a partir de algum ponto de referência, que, a nosso ver, nesse caso, é um processo já enunciado, que o narrador toma como centro momentâneo, de onde enuncia um outro processo, como passado, presente ou futuro em relação a essa fase atual.

Como se percebe, nesse ponto, nossa interpretação segue um caminho diferente do traçado na argumentação de Bronckart (2003). Entendemos que o autor toma como um mesmo parâmetro o eixo de referência temporal e a fase atual do processo narrativo. Quando está se referindo à localização isocrônica, ele afirma que os processos são localizados em relação ao eixo de referência temporal. Como fica claro no início do próprio trecho acima, esse eixo de referência temporal é constituído pelo decorrer do processo narrativo. Quando o autor está se referindo às localizações retroativa e projetiva, o processo é situado em relação à fase atual do processo narrativo. Argumentamos que a fase atual do processo de textualização (narrativo, no trecho) não corresponde ao que Bronckart (2003) tem chamado eixo de referência temporal. Não percamos de vista o fato de que esse eixo, como mesmo define Bronckart (2003), é global e corresponde ao decorrer ou à duração do processo de textualização e, portanto, envolve todas as fases desse processo e não só a fase atual. Dessa maneira, estamos identificando dois parâmetros diferentes: o eixo de referência global do tipo de discurso e o ponto de referência que define uma atualidade no processo de enunciação, que, no processo narrativo, constitui-se momentaneamente de um determinado processo já apresentado. 
Para exemplificar, no trecho acima, o eixo de referência global tem início com o primeiro processo enunciado, passou (duas semanas). A partir daí se desenvolve pela apresentação de vários outros processos e tem seu fim no último processo enunciado, ia afrontar. Ressaltamos que o eixo de referência global é constituído de todos os processos enunciados. Reparemos que, como Bronckart (2003) afirma, muitas vezes os processos são apresentados em uma ordem que parece reproduzir a dos acontecimentos da história narrada, do que decorrem localizações isocrônicas como as das formas verbais no perfeito (passou, teve, entreteve, foi dado, embarcou) e imperfeito do indicativo (afluía, era, esfregava e afirmava). Em outros casos, os processos são apresentados em ordem diferente da ordem da história, do que decorrem localizações heterocrônicas, retroativas, com as formas do mais-que-perfeito (tinha nascido, tinha exercido, tinha mudado, tinha prevalecido), e projetivas, com as formas perifrásticas de futuro do pretérito (ia se produzir, ia afrontar).

A partir da nossa consideração da existência do parâmetro fase atual do processo de textualização (narrativo, no caso), as localizações isocrônicas marcam processos como alinhados temporalmente a esse parâmetro, com uma perspectiva de presente em relação a ele. No trecho acima, a forma verbal passou (duas semanas) assume a fase atual do processo narrativo e as outras formas verbais do parágrafo (teve, entreteve, foi dado, afluía, era) são apresentadas alinhadas temporalmente a ela, com a perspectiva de presente.

Com a expressão de volta, que no contexto equivale a um processo, especificado pela expressão temporal no mês de março, inaugura-se uma nova fase atual do processo narrativo. $\mathrm{O}$ narrador se detém ali ${ }^{13}$ e estabelece uma localização isocrônica dos processos esfregava e afirmava em relação a essa fase. Além disso, estabelece uma localização heterocrônica: apresenta outro processo usando uma forma perifrástica de futuro do pretérito, ia se produzir, localizando o evento expresso nela com uma perspectiva de futuro em relação à fase atual do processo narrativo.

Com o processo morreu, especificado por outra expressão temporal, no começo de maio, tem-se uma nova fase atual do processo narrativo. Outros quatro processos, tinha nascido, tinha exercido, tinha mudado e tinha prevalecido, são então apresentados com uma perspectiva de passado relativamente a ela. A seguir, o processo embarcou, especificado pela expressão no dia 26 de maio, é tomado pelo narrador como uma nova fase atual do processo narrativo e outro processo, ia afrontar, é apresentado com uma perspectiva de futuro em relação a ela.

Reparemos que a fase atual do processo de textualização não se confunde com o que estamos chamando de eixo de referência temporal local. Esse tipo de eixo coexiste com a fase atual do processo de textualização, geralmente especificando sua localização no eixo de referência global, como as expressões temporais no mês de março, no começo de maio, no dia 26 de maio. Assim, é possível termos atuando, ao mesmo tempo, quatro tipos de parâmetros de localização: o parâmetro fonte, que é o processo, dois parâmetros a partir dos quais a temporalidade do processo é situada, o eixo de referência temporal global e fase atual do processo de textualização, e outro, o eixo de referência temporal local, que especifica essa temporalidade, sendo que os três primeiros são gerais, estando sempre presentes.

O parâmetro fase atual do processo de textualização pode coincidir com o momento da fala, de Reichenbach (1947), ou a duração de produção, de Bronckart (2003), mas não corresponde a

\footnotetext{
13 Uma discussão importante, mas que não poderemos travar aqui, diz respeito aos motivos que levam o narrador a eleger determinado processo como fase atual do processo narrativo e tomá-lo como ponto fixo para apresentar outros processos relativamente a tal ponto. Interessante é que esse ponto parece equivaler a uma espécie de "momento da fala" do narrador e também que parece haver não só um "momento da fala" do narrador, mas um "local da fala" do narrador. É o que parece explicitar-se com o uso do verbo vir no exemplo acima: o narrador denuncia seu ponto de localização espacial de onde apresenta os fatos: a França.
} 
eles. Comrie (1985), ao diferenciar tempo absoluto e tempo relativo, pondera que uma referência absoluta é ilusória, pois sempre o evento é situado em relação a um ponto qualquer, quer seja o momento da fala, quer não. Esse parâmetro que estamos postulando se adéqua a essa consideração. A fase atual do processo de textualização pode coincidir com a duração associada ao ato de produção, contudo, quando tal duração não for pertinente, como nos tipos de discurso do narrar, a fase atual coincide com outro ponto, um processo já apresentado.

Em resumo, nos tipos de discurso da ordem do narrar, o eixo de referência temporal global é estabelecido a partir de uma origem espaçotemporal (por exemplo, no dia 22 de setembro de 1920, numa manhã de sol de outubro). A origem espaço-temporal instaura o ponto de início do eixo de referência temporal global. Tem início o processo narrativo, a atividade de contar, de narrar os eventos, de apresentá-los em uma determinada ordem de sucessão. Essa apresentação, já que constitui um processo, é desenvolvida em várias fases, que, às vezes, são especificadas com expressões temporais (do tipo dois dias depois, uma semana mais tarde etc.), eixos de referência locais que as localizam mais precisamente no eixo de referência global. Tais fases vão correspondendo a certos processos apresentados, que, momentaneamente, vão sendo tomados como centro do processo narrativo. Outros processos podem ser, então, apresentados como simultâneos a esses processos constituintes das fases atuais. O narrador apresenta tais processos de uma perspectiva de presente em relação à fase atual, que é identificada pela forma verbal em que o processo é expresso: pretérito imperfeito ou pretérito perfeito do indicativo, no português. ${ }^{14} \mathrm{~A}$ apresentação dos processos vai acompanhando cronologicamente, pari passu, a ordem em que ocorreram na própria história narrada.

Entretanto, isso não acontece sempre. O narrador pode se fixar em uma dessas fases do processo narrativo, parar em um ponto da sucessão cronológica dos processos, e, dessa fase, apresentar outros processos, situando-os como anteriores ou posteriores a ela. A fase atual do processo narrativo e o processo apresentado não coincidem mais. Assim, o processo é apresentado de uma perspectiva de passado ou de futuro, que é identificada pelo uso de determinadas formas verbais: do pretérito mais-que-perfeito do indicativo, quando o processo é situado como anterior à fase atual do processo narrativo, na perspectiva de passado; e do futuro do pretérito do indicativo e formas variantes, quando o processo é situado como posterior à fase atual do processo narrativo, na perspectiva de futuro.

Nos tipos de discurso do expor, o eixo de referência temporal global não é baseado em uma origem espaçotemporal. Pode assumir como centro (e não como início) a duração de produção, como ocorre no discurso interativo. É um centro fixo, que perdurará durante todo o processo expositivo. Podem ocorrer eixos de referência locais, advérbios e expressões temporais (amanhã, ontem, daqui a 5 anos, quando amanhecer) que retomam a duração associada ao ato de produção, servindo como especificadores de processos relativamente ao centro do eixo de referência temporal global. Entretanto, o eixo de referência temporal global pode não assumir a duração de produção como centro, deixando indefinida sua relação com esse parâmetro. O eixo global terá uma extensão ilimitada e pode ter como centro momentâneo qualquer fase que o componha. É o que acontece no discurso teórico.

A fase atual do processo de textualização pode, então, coincidir com a duração associada ao ato de produção quando ela for tomada como centro do eixo de referência temporal global. Quando o eixo de referência temporal global não tem como centro a duração do ato de produção, a fase atual

\footnotetext{
${ }^{14}$ A distinção entre esses tempos nessa função é de caráter aspectual e ajuda a definir as funções de contraste: o perfeito coloca um evento em primeiro plano em relação a outros eventos, e o imperfeito, em segundo plano.
} 
do processo expositivo coincidirá com um processo já apresentado, à semelhança do que ocorre nos tipos de discurso do narrar. No português, de forma geral, as formas do presente do indicativo são usadas para marcar um evento como simultâneo à fase atual do processo expositivo, as do perfeito do indicativo, como anterior, e as do futuro do presente e formas variantes, como posterior a ela.

Se analisarmos, usando os parâmetros conforme descritos acima, o exemplo de Bronckart, "Amanhã, Pedro vai (irá) a Lausanne", que provavelmente faria parte de um texto de discurso interativo, poderemos considerar as duas formas verbais, vai e irá, como variantes expressando uma mesma função: posterioridade do processo de ir em relação à fase atual do processo expositivo, que coincidiria, no caso, com a duração do ato de produção, tomada como centro do eixo de referência global. O eixo de referência local amanhã especifica a localização do processo em relação ao centro do eixo de referência global. Os três parâmetros gerais, processo, eixo de referência temporal global, fase atual do processo expositivo, e mais um parâmetro extra, um eixo de referência local, são usados na definição da função de temporalidade.

Caso retomemos também o exemplo de Corôa (1985), veremos que a futuridade ou relação de posterioridade que é expressa em "Na manjedoura, nascia aquele que seria o salvador do mundo", própria de um texto que estivesse recontando, narrando, de alguma forma a história bíblica, é semelhante à expressa na frase "Na manjedoura, nasce aquele que será o salvador do mundo", dita, por exemplo, por José a Maria, no exato momento do nascimento de seu filho. O que muda é o tipo de discurso tradutor de um mundo discursivo específico de que cada enunciado é atualizador. A relação entre os pontos que definem a posterioridade em seria e será é a mesma; é o estatuto dos pontos em cada tipo de discurso, do ponto de vista de sua constituição, que é diferente: o processo será é posterior à fase atual do processo de textualização, que coincide com o centro do eixo de referência global do discurso interativo constituído pela duração do ato de produção. $\mathrm{O}$ processo seria, também é posterior à fase atual do processo de textualização, mas que coincide, nesse caso, com um processo já apresentado (nascia): o eixo de referência temporal global da narração não tem um centro explícito fixo. A origem espaçotemporal marca apenas o início desse eixo e qualquer das fases que o compõem pode assumir uma posição atual de centro, a partir da qual o processo é apresentado.

A partir do exposto, apresentamos abaixo representações gerais da localização dos parâmetros que propomos, processo $(\mathrm{P})$, eixo de referência temporal global $\left(\mathrm{ER}_{\mathrm{G}}\right)$, fase atual do processo de textualização (expositivo/narrativo) (FA) ${ }^{15}$ e eixo de referência temporal local $\left(\mathrm{ER}_{\mathrm{L}}\right)$, na linha temporal dos mundos discursivos do expor e do narrar. Começamos pela linha dos mundos do expor:

Figura 1 - Linha temporal dos mundos do expor

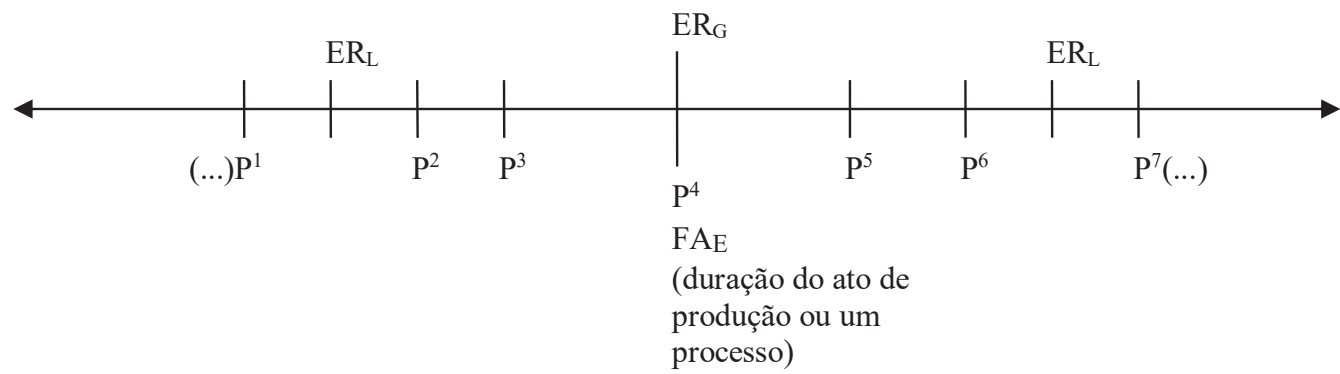

\footnotetext{
${ }^{15}$ Quando nos referirmos especificamente ao processo expositivo ou narrativo, adicionaremos a FA, respectivamente, 'E' ou ' $N$ ' subscritos: $\mathrm{FA}_{\mathrm{E}}, \mathrm{FA}_{\mathrm{N}}$.
} 
O eixo de referência temporal global $\left(\mathrm{ER}_{\mathrm{G}}\right)$ do mundo do expor, que não tem início ou fim explicitados, pode ter como centro uma fase atual do processo expositivo $\left(\mathrm{FA}_{\mathrm{E}}\right)$ coincidente com a duração de produção (no discurso interativo) ou com um processo (no discurso teórico). Com base na $\mathrm{FA}_{\mathrm{E}}$, são localizados os processos $(\mathrm{P})$. Pode haver eixos de referências locais $\left(\mathrm{ER}_{\mathrm{L}}\right)$, que precisam a localização dos processos. Processos localizados como simultâneos à $\mathrm{FA}_{\mathrm{E}}$, como $\mathrm{P}^{4}$, são expressos com formas do presente do indicativo. Processos localizados como anteriores, à esquerda de $\mathrm{FA}_{\mathrm{E}}$, como $\mathrm{P}^{3}$, são atualizados com formas do pretérito perfeito do indicativo, e os processos localizados como posteriores, à direita de $\mathrm{FA}_{\mathrm{E}}$, como $\mathrm{P}^{5}$, com formas do futuro do presente do indicativo e variantes. Segue, agora, a representação dos parâmetros na linha temporal dos mundos do narrar:

Figura 2 - Linha temporal dos mundos do narrar

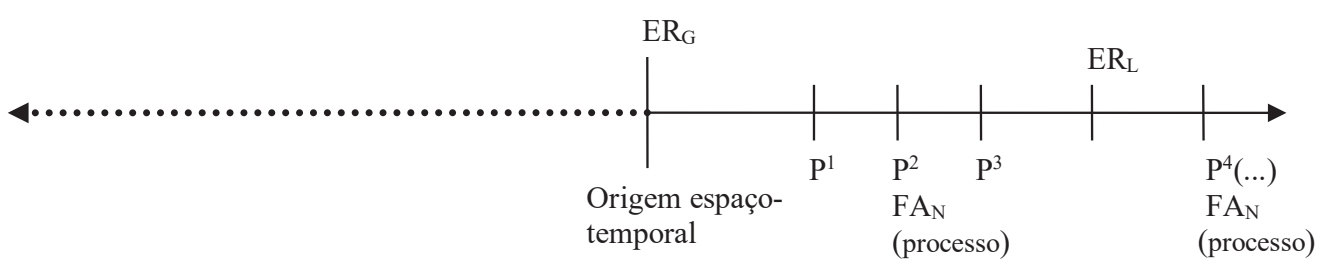

O eixo de referência temporal global $\left(\mathrm{ER}_{\mathrm{G}}\right)$ dos mundos do narrar tem início com uma origem espaçotemporal e não tem explicitado um centro. Determinados processos podem ser tomados como centros momentâneos no desenvolvimento do processo narrativo, constituindo as fases atuais do processo narrativo $\left(\mathrm{FA}_{\mathrm{N}}\right)$. Os outros processos $(\mathrm{P})$ são, então, localizados a partir dessas fases atuais. Alguns processos são apresentados como simultâneos, de uma perspectiva de presente, em relação à $\mathrm{FA}_{\mathrm{N}}$, por exemplo, $\mathrm{P}^{2}$, outros como anteriores à $\mathrm{FA}_{\mathrm{N}}$, por exemplo, $\mathrm{P}^{1}$, e outros como posteriores à $\mathrm{FA}_{\mathrm{N}}$, por exemplo, $\mathrm{P}^{3}$. Os primeiros são expressos com formas do pretérito imperfeito ou do pretérito perfeito do indicativo, os segundos, com formas do mais-que-perfeito do indicativo, e os últimos, com formas do futuro do pretérito do indicativo e variantes. A parte pontilhada da linha temporal expressa a possibilidade de $\mathrm{ER}_{\mathrm{G}}$ ser ampliado se for feita referência a processos anteriores à origem espaçotemporal. Entendemos, assim, que esses parâmetros podem ser usados para a análise e definição dos tempos verbais.

\section{CONSIDERAÇÕES FINAIS}

Alguns estudiosos, a exemplo de Benveniste (1995), Weinrich (1974) e Bronckart (2003), propõem tratar os tempos verbais não como geralmente são considerados, a partir das relações dessa categoria com o tempo cronológico, mas de uma dimensão mais ampla, textual-discursiva, que os relaciona com os mundos discursivos de que se originam os textos produzidos nas mais variadas situações de interação verbal.

Os tempos verbais, dentro dessa perspectiva alternativa, teriam como função principal atualizar os diferentes tipos de discurso, associados aos mundos discursivos, que compõem os textos. Mais especificamente, dentro da proposta de Bronckart (2003), ao lado de outros recursos linguísticos, ajudariam a marcar se os textos produzidos pertenceriam aos mundos do expor, implicado (discurso interativo) ou autônomo (discurso teórico), ou aos mundos do narrar, implicado (relato interativo) ou autônomo (narração). 
Dentro de cada um dos mundos discursivos, que são organizados com base em coordenadas espaçotemporais específicas, os tempos verbais podem ser vistos também a partir de uma dimensão que comporta as relações de anterioridade, simultaneidade e posterioridade dos processos verbais em relação a pontos de referência. Corôa (1985), fundamentada na proposta de Reichenbach (1947), formula uma simulação dos modos de expressão do tempo verbal em português, relacionando o momento do evento (ME), o momento da fala (MF) e o momento de referência (MR).

Fundamentando-nos na perspectiva dos mundos discursivos e dos tipos de discurso e na da existência dos pontos teóricos relativos na linha do tempo, reformuladas e adaptadas em certos aspectos, desenvolvemos a tese central do artigo: a constituição desses pontos depende das características dos tipos de discurso, de maneira que os tempos verbais devem ser analisados e definidos a partir da consideração de que os tempos verbais então organizados não em um sistema temporal único, mas em subsistemas característicos de cada tipo de discurso. A partir do exposto, propomos os seguintes parâmetros baseados nos quais os tempos verbais podem ser estudados: processo $(\mathrm{P})$, eixo de referência temporal global $\left(\mathrm{ER}_{\mathrm{G}}\right)$, fase atual do processo de textualização (expositivo/ narrativo) (FA) e eixo de referência temporal local $\left(\mathrm{ER}_{\mathrm{L}}\right)$.

Ressaltemos os limites deste trabalho que, por seu cunho teórico, não apresenta uma análise dos parâmetros postulados a partir de textos produzidos em situações discursivas concretas, o que poderia revelar, inclusive, a necessidade de ajuste na proposta teórica. Apesar de tais parâmetros terem sido utilizados para a definição da função de expressão do futuro em português no trabalho de Alves (2011), precisam ser testados em estudos posteriores que tenham como objeto outras funções temporais.

\section{REFERÊNCIAS}

ABREU, Maria do Socorro Cardoso de. Referência temporal em narrativas escritas infantis. Dissertação (Mestrado) - Universidade Federal do Ceará, Fortaleza, 1998.

ADAM, Jean-Michel. Les textes types et prototypes. Paris: Nathan, 1992.

ALVES, Thiago Gil Lessa. A expressão da futuridade nos tipos de discurso do expor e do narrar a partir de textos de língua falada e escrita cearenses. 261p. Tese (Doutorado em Linguística) Universidade Federal do Ceará, Fortaleza, 2011.

BENVENISTE, Emile. Problemas de linguística geral I. 4.ed. Campinas: Pontes, 1995.

BRONCKART, Jean-Paul. Atividades de linguagem, textos e discursos: por um interacionismo sócio-discursivo. São Paulo: EDUC, 2003.

CAMARA JR., Joaquim M.. Estrutura da língua portuguesa. Petrópolis: Vozes, 1994.

COMRIE, B. Tense. Cambridge: Cambridge University Press, 1985.

CORÔA, Maria Luiza Monteiro Sales. O tempo nos verbos do português: uma introdução à sua interpretação semântica. Brasília: Thesaurus, 1985. 
DUCROT, O. Le dire et le dit. Paris: Minuit, 1984.

FLEISCHMAN, S. The future in thought and language. Cambridge: Cambridge University Press, 1982.

KOCH, I. G. V.. Argumentação e linguagem. São Paulo: Cortez, 1984.

KOCH, I. G. V.. A coesão textual. São Paulo: Cortez, 1989.

KOCH, I. G. V.. A inter-ação pela linguagem. São Paulo: Contexto, 1992.

MACHADO, Ana Raquel. $O$ diário de leituras: a introdução de um novo instrumento na escola. 263p. Tese (Doutorado em Lingüística Aplicada ao Ensino de Línguas) - Faculdade de Letras, Pontifícia Universidade Católica, São Paulo, 1995.

OLIVEIRA, Joseane Moreira de. O futuro da língua portuguesa ontem e hoje: variação e mudança. 2006. 254p. Tese (Doutorado) - Curso de Letras, Universidade Federal do Rio de Janeiro, Rio de Janeiro, 2006.

REICHENBACH, Hans. Elements of symbolic logic. New York: Macmillam Company, 1947.

REINHART, T. Principles of gestalt perception in temporal organization of narrative texts. Linguistics, v. 22, p. 779-809, 1984.

WEINRICH, Harald. Estructura y función de los tiempos en el lenguage. Madrid: Gredos, 1974. 